\title{
Cost-Effectiveness Comparison on Different Assistance Approaches
}

\author{
- Base on the FAO Agricultural Rehabilitation and Restoration Program after \\ Wenchuan Earthquake
}

\author{
Hua Guo, Yuansheng Jiang* \\ College of Economics and Management, Sichuan Agricultural University, Chengdu, China \\ Email: huaguohua@sina.com, *yjiang15@yahoo.com.cn
}

Received July 2, 2012; revised August 2, 2012; accepted August 10, 2012

\begin{abstract}
The Food and Agriculture Organization of United Nations (UNFAO) adopted two assistance approaches which named the Direct Inputs Distribution (DID) and Agricultural Inputs Voucher (AIV) to assist the disaster affected farmers after the Wenchuan massive earthquake in Sichuan, China (Jiang, Guo, 2010) [1]. After carrying out 1) the beneficiaries' field survey targeted on the earthquake affected households including both assistance recipients and non-recipients, and 2) the focus group interview of the administrative personnel in FAO Chengdu office, Department of Agriculture (DoA), Bureau of Agriculture (BoA), dealers participated in the program, the paper analyzed the total cost and effectiveness of those two approaches, by comparing the mean E:C ratios, which were 1.564 and 1.206 respectively. The results indicated that the AIV programs were more effective in assisting agriculture rehabilitation as compared to the DID programs.
\end{abstract}

Keywords: Assistance; Cost; Effectiveness

\section{Introduction}

Right after the 5.12 Wenchuan massive earthquake, numerous of emergency assistances were delivered to the disaster areas in Sichuan, China. Those assistances were provided and implemented by varieties of non-government organizations such as the Food and Agriculture Organization (FAO), the United Nations Development Programme (UNDP), the International Federal of Red Cross and Red Crescent Societies (FIRC) and the International Labor Organization (ILO). With regards to the assistance approaches, besides the traditional assistances, some new methods were adopted for the first time. In which, the Agriculture Input Voucher (AIV) program that was successfully implemented in FAO Sichuan.

Post-earthquake Agricultural Rehabilitation and Restoration Programs were believed an innovation in postearthquake assistance. Compared to the traditional Direct Inputs Distribution (DID) assistance, the AIV program considered a variety of farmers' demand for agro-inputs (Minot, 2009) [2], and beneficiaries had the privilege to choose the agro-inputs they need most. Notably, the AIV program was widely welcomed by the assistance received people (Longley, 2008) [3], but whether it was the

*Corresponding author. right answer or the right approach for the post-earthquake rehabilitation was still in question. In this paper, by using the Cost-Effectiveness Analysis (CEA), we would discuss which approach was more effective.

\section{Analytical Method and Data Resources}

Traditionally, CEA is a specific type of economic analysis in which all costs are related to a single, common effect. Decision makers can use it to compare different resource allocation options in like terms. A general misconception is that CEA is merely an approach to find the least expensive alternative or get the "most bang for the buck”. In reality, CEA is a comparison tool. It not only indicates a clear choice, but also evaluates options quantitatively and objectively based on a defined model. CEA can compare any resource allocation with measurable outcomes. The analysis, however, and mostly ignores dynamic growth impacts, either positive or negative (Andrew Dorward, 2008) [4]. The difficulties in a cost effectiveness analysis of the program are considerable, such as how to quantify the received benefits from the program and the cost of the implementation. This analysis is not to ascertain the precise cost and effectiveness, but to compare the effectiveness and costs ratio within the two assistance approaches in order to determine the 
response in the costs if the assistance (effectiveness) were to increase by $1 \%$. The cost-effectiveness ratio is simply the sum of all benefits divided by the sum of all costs.

$$
\mathrm{CER}=\frac{\sum \text { Effectiveness }}{\sum \text { Cost }}
$$

This is comparable to a return on investment calculation; however, the benefits are not measured in terms of just money, but in a ratio that incorporate both outcomes and money. Therefore the purpose of the analysis is to inform decision makers on whether or not the AIVP should be adopted, or if the DID is a better option.

\section{Quantifying the Cost and Effectiveness}

The cost effectiveness analysis computes the costs and effectiveness of the AIVP and DID respectively, following the definitions in the Tables $\mathbf{1}$ and $\mathbf{2}$.

Costs: the costs of the program implementation could be divided into two parts, the direct cost and the indirect cost.

Effectiveness, we defined the effectiveness as the total production valued at the market price and the additional profits of the dealers under the program.

\subsection{The Costs}

The direct costs depend on the total assistance fund. For the program, the total financial support included US $\$ 212150.9$ (RMB 1,427,900 Yuan) for AIVP, 19\% of the total assistance fund; and US \$900,427 (RMB 6122903.6 Yuan) for DID, counting for $81 \%$ of the total assistance fund (at the exchange rate of US \$1 = RMB 6.8 Yuan.

The indirect costs originated from the program implementation process comprise: a) the cost of the FAO for domestic experts and ERCU Chengdu, b) the expenses of the government (funded by FAO) and, c) the farmers' loss of working time replaced by the training and voucher purchasing.

1) The cost of the FAO for domestic experts and ERCU Chengdu

Table 3 shows the detailed costs of the FAO for domestic experts and ERCU Chengdu.

For both of the AIVP and DID, also based on the data surveyed from the ERCU, there were in total 5 national experts under the leadership of the ERCU, 3 for the AIVP and 2 for the DID. On average each national expert went on mission trips 30 times. The mean expenses on transportation were 119 Yuan while for accommodation was 100 Yuan per day. In that case, the total cost of the travel expenses for AIVP were 19,710 Yuan while for DID the expenses were 13,140 Yuan total cost 32,850 Yuan. Two employees were hired by the ERCU Chengdu, for them the travel expenses on AIVP were 115 Yuan for transportation fees per journey and RMB 100 Yuan for accommodation per journey. One person was paid for all the 25 mission trips during the implementation of the program. So the total travel costs were 5375 Yuan for the AIVP. Meanwhile, only 15 mission trips cost 3225 Yuan were paid for the DID program, therefore in total the expense on this item was 8600 Yuan.

For the salaries of the experts, US \$50 (RMB 340 Yuan at the exchange rate of US $\$ 1=$ RMB 6.8 Yuan) would be paid per day by FAO. From the data collected based on the interview with the experts, 90 days was the average work load for each person. So the FAO would have paid RMB 91,800 Yuan (90 days $\times 340$ ) to the experts hired for the AIVP, and RMB 61,200 Yuan to the experts of the DID program.

The employees salaries paid by the FAO were RMB 244,800 Yuan under the AIVP, and RMB 163,200 Yuan under the DID program.

Table 1. Definition of the cost.

\begin{tabular}{llll}
\hline & \multicolumn{1}{c}{ FAO } & BoA & DoA \\
\hline Direct cost & $\begin{array}{l}\text { The assistance fund given to the beneficiaries } \\
\text { The cost of administration and operation of the ERCU Operation and } \\
\text { Indirect cost } \\
\text { Chengdu and the salaries for the domestic experts }\end{array}$ & $\begin{array}{l}\text { Operation and } \\
\text { management cost }\end{array}$ & $\begin{array}{l}\text { Loss of working and farming time replaced } \\
\text { manemt cost by the training and voucher purchase }\end{array}$ \\
\hline
\end{tabular}

Table 2. Definition of the effectiveness.

\begin{tabular}{|c|c|c|c|c|c|c|c|c|}
\hline & & \multicolumn{4}{|c|}{ Farmers } & \multicolumn{3}{|c|}{ Dealers } \\
\hline \multicolumn{2}{|c|}{ Effectiveness } & \multicolumn{4}{|c|}{ Outputs of the farming production valued at the market price } & \multicolumn{3}{|c|}{ Profits of the dealers under the program } \\
\hline & \multirow{2}{*}{ No. } & \multicolumn{2}{|c|}{ Travel expense (RMB) } & \multicolumn{2}{|c|}{ Salaries (experts \& staff) (RMB) } & \multicolumn{2}{|c|}{ Office expenses (RMB) } & \multirow{2}{*}{ In sum (RMB) } \\
\hline & & AIVP & DID & AIVP & DID & AIVP & DID & \\
\hline National experts & 5 & 19,710 & 13,140 & 91,800 & 61,200 & & & 185,850 \\
\hline ERCU Chengdu & 2 & 5375 & 3225 & 244,800 & 163,200 & 7800 & 5200 & 429,600 \\
\hline In total & 7 & 25,085 & 16,365 & 336,600 & 224,400 & 7800 & 5200 & 615,450 \\
\hline
\end{tabular}

Data source: household survey database. 
The office expenses were composed of the electricity cost of 250 Yuan $\times 20$ months $=$ RMB 5000 Yuan, stationery of 20 Yuan $\times 10$ Books $\times 20$ months +50 Yuan $\times$ 20 months $=5000$ Yuan, drinking water 10 Yuan $\times 5$ barrels $\times 20$ months $=1000$ Yuan, and others 100 Yuan $\times$ 20 months $=2000$ Yuan: in sum RMB 13,000 Yuan.

2) The expenses of the relevant governments

To ensure the smooth implementation of the program, FAO offered US $\$ 40,000$ to the Department of Agriculture Sichuan Province to support the programs including the program TCP-CPR-3108, the program OSRO-CPR-801-BEL, the program OSRO-CPR-802-LUX, and the program OSRO-CPR-803-SWE. Table 4 shows the detailed expenses of the government. The budget was distributed under the principle of 1) to what extent the pilot counties were affected by the disaster, 2) infrastructure conditions, 3) the assistance value arranged in each county, and 4) the working hours etc.

Here the travel expenses included the cost of the DoA officials' mission trips to the counties received assistances and trips for the farmers' demand, market price and dealers comparison surveys conducted by the BoA in each counties. For the DoA Sichuan, 40 journeys to the different pilot counties were paid for. From Chengdu to Shifang the distance is $83 \mathrm{~km}$, to Anxian the distance is $120 \mathrm{~km}$, to Beichuan is $153 \mathrm{~km}$, to Mianzhu is $106 \mathrm{~km}$, and to Jiangyou is $144 \mathrm{~km}$. The mean distance between Chengdu and the pilot counties is therefore $121.2 \mathrm{~km}$ and $8 \mathrm{~L}$ fuels would last for approximately $100 \mathrm{~km}$. The price of the fuel was at RMB 7.14/L . On average the highway toll cost RMB 100 Yuan/trip. Thus, the cost of the transportation for DoA Sichuan can be computed as $121.2 \mathrm{~km} \times 2 \times 0.08 \mathrm{~L} / \mathrm{km} \times 7.14$ Yuan/L $\times 40$ trips + 100 Yuan $\times 40$ trips $=9538.36$ Yuan. Accommodation cost was about 150 Yuan per person per day, so the total expenses were 150 Yuan $\times 40$ days $=6000$ Yuan.

The transportation expenses of each BoA can be seen in the Table 4 above. For BoA Mianzhu, the travel for AIVP was in total $800 \mathrm{~km}$ with expenses of 456.96 Yuan, while for the DID it was 350 Yuan. For BoA Anxian, the travel distances for AIVP was $1200 \mathrm{~km}$ in total, and cost
685.44 Yuan, while for DID it was 360.82 Yuan. For BoA Shifang, there were 8 trips made which cost 411.26 Yuan. For BoA Jiangyou, 9 trips were paid for, that cost 205.63 Yuan. And for the BoA Beichuan, the level of travel expenses ranked the highest, with 10 trips costing 913.92 Yuan.

The operation costs of the DoA Sichuan comprised the offering of facilities and equipment such as offices, computers and office furniture to the ERCU etc. 2000 Yuan $\times 20$ months $+12,000$ Yuan $+20,000$ Yuan $=$ 72,000 Yuan, printing of vouchers $(2245$ pieces $\times 2+$ 2245 pieces $) \times 0.5$ Yuan/piece $=3367.5$ Yuan, and the working subsidies for the DoA staff, 10,000 Yuan. Total expenses: 85367.5 Yuan. Expenses for AIVP were 52927.85, and DID 32439.65 Yuan. Also for the AIVP, 7 persons were needed for the voucher distribution, the supervision of the voucher purchasing and the other related AIVP works. 3000 Yuan was paid to each person, so RMB 21,000 Yuan were spent on those items. For the implementation of the AIVP, operation costs contain the subsidy for the working staff, allowances for farmers, rental for meeting rooms and facilities, stationery, printing and copying charges, advertisement charges, etc. For BoA Mianzhu the subsidy for the working staff was 5 persons $\times 20$ Yuan/person $\times 9$ times $=900$ Yuan; rental for meeting room and facilities was 500 Yuan $\times 9$ times $=4500$ Yuan; printing and copying charges were 1875 copies $\times 0.1$ Yuan $=187.5$ Yuan; advertisement expenses 200 Yuan $\times 9$ times $=1800$ Yuan. Total: 7387.5 Yuan.

During the whole process of the program operation, BoA Mianzhu employed 4 persons comprising 2 skilled laborers (150 Yuan/day $\times$ person) and 2 unskilled-laborers (50 Yuan/day $\times$ person) for the surveys on demand, market price and dealers, and as well as for the supervision on voucher distribution and purchase that lasted 15 days. So the salaries paid by BoA were $2 \times 100$ Yuan/person $\times 15$ days $+2 \times 50$ Yuan/person $\times 15$ days $=$ 4500 Yuan. The operation cost of DID was 905.54 Yuan. The costs of BoAs in other counties were calculated by using the same standard and described in Table 4. As shows in Table 4, based on the survey data, in total the

Table 4. Expenses of the relevant governments.

\begin{tabular}{cccccc}
\hline & Program & Travel expenses (RMB) & Operation costs (RMB) & Employees' wages (RMB) & In sum (RMB) \\
\hline \multirow{2}{*}{ DoA Sichuan } & AIVP & 9633 & 52,928 & 21,000 & 83,561 \\
& DID & 5905 & 32,440 & 0 & 38,345 \\
BoA Mianzhu & AIVP & 457 & 7387 & 4500 & 12,344 \\
& DID & 350 & 905 & 0 & 1255 \\
BoA Anxian & AIVP & 1387 & 22,432 & 13,664 & 37,483 \\
& DID & 1063 & 2749 & 0 & 3812 \\
BoA Shifang & DID & 3792 & 9808 & 0 & 13,600 \\
BoA Jiangyou & DID & 3500 & 10,100 & 0 & 13,600 \\
BoA Beichuan & DID & 18,956 & 49,044 & 0 & 68,000 \\
In total & & 45,043 & 187,793 & 39,164 & 272,000 \\
\hline
\end{tabular}

Data source: household survey database. 
expenses for the relevant governments were close to RMB 272,000 Yuan.

3) The farmers' loss of working hours due to training and voucher purchasing

Through out the AIV programs conducted in Mianzhu and Anxian, a total of 2245 households received the assistance. It was assumed that one member in each household received the training given by the National experts and spent half a day to purchase the agro-inputs. And the loss of working hours was the cost of the opportunity in receiving assistance. RMB 60 Yuan was the salary for one farmer's work per day. So the farmers' loss of working hours replaced by the training and the voucher purchasing could be computed as 60 Yuan $\times$ 2245 households $=134,700$ Yuan.

\subsection{The Effectiveness}

As mentioned previously, effectiveness was defined as the total production valued at the market price and the additional profits of the dealers' under the program.

For the beneficiaries, the effectiveness can be quantified by the following method. By analyzing the AIVP assistance households' output per household, then comparing it with the output of the Non-aided households, we may compute the additional output of the AIVP households. As shows in the Table 5 the total number of randomly selected AIVP assistance households was 204 households with total output valued at RMB 1,008,753
Yuan; in addition, there were 37 Non-aided households at the same place with total output valued at RMB 1315599.9 Yuan. The average additional output generated in value would then be RMB 1388.12 Yuan/household. With the result above, total amount of the additional value is 1388.12 Yuan $\times 2245$ households $=\mathrm{RMB}$ 3116329.4 Yuan. Using the same methodology as for AIVP, the total additional output value for DID is RMB 17,239,867 Yuan, and RMB 2688.71 Yuan per household (see Table 6).

According to the internet survey and field investigation, for the dealers at each level in earthquake disaster areas, $10 \%$ was the profit rate. Following the principle of benefit to both farmers and dealers during the implementation of the program, and based on the data collected, the dealers lowered the price of the agro-inputs by about $2 \%$ on average. So the profit rate the suppliers obtained was about $8 \%$. The total sales volume was RMB 611,000 Yuan, so the additional profits the dealers accrued from the AIVP was 1,427,900 Yuan $\times 8 \%=$ 114,232 Yuan. The manufactures' extra profits received from the program was 6122903.6 Yuan $\times 8 \%=489,832$ Yuan.

\section{Cost Effectiveness Ratio and Its Analysis}

Tables 7 and $\mathbf{8}$ set out the total cost and sum of the effectiveness we calculated above.

Cost-effectiveness ratios calculated for the whole pro-

Table 5. Output value led by the AIVP (RMB).

\begin{tabular}{cccccc}
\hline & Total outputs value & Outputs value per hh & Additional outputs value per hh & Number of hhs & Total additional outputs value \\
\hline AIVP & $1,008,753$ & 4944.86 & 1388.12 & 2245 & 3116329.4 \\
Non-aided & 131599.9 & 3556.75 & - & - & - \\
\hline
\end{tabular}

Data source: household survey database.

Table 6. Output value led by the DID (RMB).

\begin{tabular}{cccccc}
\hline & Total output value & Output value per hh & Additional output value per hh & Number of hhs & Total additional output value \\
\hline DID & $1,484,910$ & 9899.4 & 1139.34 & 6460 & $7,360,136$ \\
Non-aided & 876,006 & 8760.06 & - & - & - \\
\hline
\end{tabular}

Data source: household survey database.

Table 7. Costs for each participator (RMB).

\begin{tabular}{cccccc}
\hline & Direct cost & \multicolumn{3}{c}{ Indirect cost } & \multirow{2}{*}{ Total } \\
\cline { 2 - 5 } & FAO assistance & ERCU & Relevant governments & Farmers’ loss & $2,065,473$ \\
AIVP & $1,427,900$ & 369,485 & 133,388 & 134,700 & 6507480.6 \\
DID & 6122903.6 & 245,965 & 138,612 & 0 & 8572953.6 \\
Total & 7550803.6 & 615,450 & 272,000 & 134,700 & \\
\hline
\end{tabular}

Data source: household survey database.

Table 8. Effectiveness led by the assistance (RMB).

\begin{tabular}{cccc}
\hline & Additional effectiveness of AIVP & Additional effectiveness of DID & Total \\
\hline Farmers & 3116329.4 & $7,360,136$ & 10476465.4 \\
Dealers \& Manufactures & 114,232 & 489,832 & 604,064 \\
\hline
\end{tabular}

Data source: household survey database. 
gram, also, AIVP and the DID program respectively with the estimates of benefits and costs outlined above.

Mean E: C ratio of the $\mathrm{FAO}$ conducted programs = $\frac{11080529.4}{8572953.6}=1.292$.

Mean E: C ratio of the AIVP $=\frac{3230561.4}{2065473}=1.564$.

Mean E: C ratio of the DID $=\frac{7849968}{6507480.6}=1.206$.

\section{Conclusions and Discussions}

By computing the ratios of effectiveness to cost in money terms of the AIVP and DID, the cost effectiveness analysis (CEA) produced a result that E-C ratios of the AIVP and DID were 1.564 and 1.206 respectively. The result indicated that given the project costs including the direct and indirect costs, AIV programs were more effective in assisting agriculture rehabilitation than DID programs did.

At the same time, a preference survey of the 454 households was used to verify the result of the cost effectiveness analysis. Statistics showed that $55.5 \%$ of the surveyed farmers preferred the AIV program over a DID program, while only $17.2 \%$ had an opposite preference. So the AIV program was much more preferable than the DID programs. This innovation could be extended to other agricultural rehabilitation and restoration programs in post disaster assistance.

\section{REFERENCES}

[1] Y. S. Jiang and H. Guo, "Innovation of International Agricultural Assistance to the Wenchuan Earthquake Areas," FAO Working Paper, FAO, 2010.

[2] N. Minot and T. Benson, "Fertilizer Subsidies in Africa-Are Vouchers the Answers,” IFPRI Issue Brief 60, IFPRI, Washington DC, 2009.

[3] C. Longley, R. Kachule, et al., "Agricultural Input Vouchers in Southern Africa: Synthesis of Research Findings from Malawi, Mozambique and Zambia,” FANRPAN Working Paper, FANRPAN, Pretoria, 2008.

[4] A. Dorward, "Evaluation of the 2006/7 Agricultural Input Subsidy Programme," Malawi Final Report, School of Oriental and African Studies, Malawi, 2008. 